\title{
Transferring knowledge and experiences from informal to formal learning contexts
}

\author{
Francisco J. García-Peñalvo \\ GRIAL Research Group, \\ Educational Research Institute, \\ University of Salamanca \\ fgarcia@usal.es
}

\author{
David Griffiths \\ Institute for Educational Cybernetics, \\ University of Bolton, UK \\ D.E.griffiths@bolton.ac.uk
}

\begin{abstract}
The purpose of this track is to analyze problems experienced with the validation of informal learning and to propose alternative approaches. There is a mismatch between the enthusiasm of policy makers and other actors for informal learning initiatives, and the lack of adoption of systems in real workplaces. The use of managerial tools, such as validation and competence catalogues, has demonstrated the danger of constraining the scope for informal learning. We would like to advance and explore other different approaches to achieve the challenge of defining a very transparent framework in which both formal and informal learning are considering as important components of the own person's knowledge base.
\end{abstract}

\section{Categories and Subject Descriptors}

\section{K.3.1 [Computer Uses in Education]}

\section{General Terms}

Human Factors.

\section{Keywords}

Formal learning; Informal learning; Competence; Knowledge management

\section{INTRODUCTION}

From our previous experience with informal learning management through the TRAILER (Tagging, Recognition, Acknowledgment of Informal Learning Experiences) project [5;8], a KA3 European project devoted to advance in informal learning recognition by the learners and acknowledgement by the institutions, we have perceived some interesting approaches and behaviors regarding the informal learning.

The main objective of TRAILER project was to incorporate the consciousness of informal learning as part of an individual's development; this starts with the identification by the learner of informal learning activities and the subsequent process in which these are made visible to the institution. This task was done by developing methodologies and tools that facilitate this process [4], making it transparent both to learners and institutions and allowing all the stakeholders involved to make the most out of these processes.

TRAILER project involved learners and institutions. 'Learners' may be workers in a workplace, or traditional learners in an educational institution. Through transparency of communication, the TRAILER environment enables discussion between the different stakeholders and institutions concerning informal learning activities, the associated competences and how this information can be exploited. In order to achieve this, a staged methodology supported by a technological framework has been deployed.

Informal learning in general and TRAILER ideas in a more specific way were successfully accepted by the individuals in both business and academic contexts, who considered a good way of collecting, recording and sharing their informal learning activities that, otherwise, could easily be forgotten.

Both in universities and in companies, there is a positive perception of the importance of the informal learning recognition, but a lack of maturity in the institutions processes and employees is also perceived to assimilate the TRAILER proposal efficiently.

Professionally, several benefits have been reported such as being helpful in managing competences within an institution as well as for human resources. However, the results showed that from the employees' point of view, the importance of informal learning recognition and its usefulness in their daily professional activity can still be improved $[10 ; 12]$.

In the universities, even though informal learning is known as very relevant in students' lives and their developments, it is still under recognized at its full potential. Regarding the students' age, it was clear that freshmen had more difficulty in understanding the added value of the informal learning and the purpose of using the tool [11]. On the other hand, so did $\mathrm{PhD}$ students, who even though demonstrating more quality usage of the tool, used it more in order to complete an assignment task than actually believing in its benefits, as can be concluded based on questions they raised about its purpose.

From the discussions with the participants in a series of focus group after the project pilots, five aspects that summarized in a meaningful way the state of perception of informal learning can be highlighted:

1. Some participants have problems to recognize some of their regular activities as being possible forms of informal learning, that is, they did not thought they were learning while doing such activities.

2. Some students have a strong opinion about the informal learning, considering it not as much valuable as formal learning undertakings.

3. A regular use of a ecosystem like TRAILER [7] will require time until it could be incorporated in the employees' daily routine, but only then we will be able 
to see its profits. Moreover, it is necessary to simplify the process of capture and tagging of informal activities, requiring the incorporation of automated tasks that help in the process.

4. When its usage within an institution will already have meaningful content of the overall of the employees, we will see its full potential from the organization perspective.

5. Employees do not perceive the meaning of win-win process and are observed by the institution, big brother effect.

Due to the conclusions from the TRAILER project, combined with other interesting and important sources (for example, the CEDEFOP "European Guidelines for Validating Informal and Non-formal Learning" [2] that contains experiences of more than 20 countries in the validation of informal and non-formal learning; the ECOTEC European Inventory of validation of nonformal and informal learning (http://www.uk.ecorys.com/europeaninventory/) that provides a catalogue of good practices in the area of validation for policy-makers; MyElvin Social Network for language practice [6]; the National Qualification Systems and EQF (European Qualifications Framework), or the TENCompetence project [1] that provides a set of tools to support lifelong learning), we may claim that informal learning is an increasingly important element in various fields, thus enhancing informal learning practices in formal contexts (informalization of formal learning) as somehow recognizing the knowledge, competencies and skills acquired informally (formalization of informal learning). On the one hand, the University is incorporating into their teaching methodologies informal aspects heavily influenced by the philosophy of social collaboration through online platforms. Moreover, in the professional sector, continuous training of employees in the workplace is favored if the informal learning flows, which undoubtedly occur in the daily life of each worker, as well as interactions among peers and colleagues from other organizations, may be recognized and leveraged. Finally, agencies and policymaker institutions, such as the European Union for example, advocate the recognition of informal learning and classify these processes as one of the major challenges for the immediate future.

The purpose of this track is to analyze problems experienced with the validation of informal learning and to propose alternative approaches, especially the detected mismatch between the enthusiasm of policy makers and other actors for informal learning initiatives, and the lack of adoption of systems in real workplaces. The use of managerial tools, such as validation and competence catalogues, has demonstrated the danger of constraining the scope for informal learning. Also, we would like to advance and explore other different approaches to achieve the challenge of defining a very transparent framework in which both formal and informal learning are considering as important components of the own person's knowledge base.

In a more specific way, the topics covered in this track are:

- Informal learning competences discovering and recognition.

- Technological ecosystem for enhancing informal learning recognition.

- Informal learning approaches in formal learning contexts.
- Semantic representations for informal learning evidences.

- Informal learning behaviors.

\section{TRACK ORGANIZATION}

This section describes in further detail the seven contributions accepted to participate in this Conference track.

\subsection{Problems and opportunities in the use of technology to manage informal learning}

As we introduced above, we perceive a mismatch between the enthusiasm of policy makers and other actors for initiatives to support the validation of informal learning, and the lack of adoption of systems in practice. This problem has been explored, with reference to the creation of the Informal Learning Collector [9] in the European Commission TRAILER project [5;8]. It is proposed that formality in learning can be usefully understood as a measure of the degree of managerial control over the learning process. It is then argued that the use of managerial tools, such as validation and competence catalogues, runs the danger of constraining the scope for informal learning. Analytics techniques offer the possibility of providing insight into practice by examining documents, without the need for formal description or tagging. However, these methods raise problems of surveillance (by companies and the state), confidentiality, and security of data. A prototype system is described which tests the feasibility of the approach.

\subsection{Formal Competence-based Assessment: on closing the Gap between Academia and Industry}

Following with the above-mentioned differences of perspectives between the Academia and the Business, for many years, we have observed industry great efforts in defining higher workplace productivity. Mostly, these efforts are exploring the field with highlighting industrial expectations and issues. However, until the appropriate selection of the competent candidates, this remains far from being realistic. From this standpoint and recognizing the inadequacy of current traditional knowledge-based assessment systems in higher education to achieve performance visibility, we think we need to rethink how we design new assessment models that can respond to the corporate requirements of the $21^{\text {st }}$ century and mirror the learners' competences. This concern has not been sufficiently investigated and only a minority provided some efforts to grant the fundamental models to assess Learners based on the standard required competences. Thus, the main output of this paper is a semantic model and a framework specification for competence-based assessment to support the formal and informal learning competences visibility.

\subsection{A Social Framework for Supporting, Evaluating and Validating Informal Learning}

The third paper of this track proposes the usage of a more social and dynamic framework for validating and promoting a learner's informal learning as a different way for validating informal learning than the proposed guidelines that have been published providing competence catalogues for direct transition from informal to formal learning. 


\subsection{Mobile Learning Adoption from Informal into Formal: An Extended TAM Model to Measure Mobile Acceptance among Teachers}

This paper proposes an extended TAM (Technology Acceptance Model) model [3] with constructs from other theories, designed for the evaluation of the acceptance of the mobile technologies by the teaching body and its implication in informal learning activities.

\subsection{Visualizing Informal Learning Behavior from Conference Participants Twitter Data}

The fifth paper in the track is related to small data research in informal learning context. Knowledge Management acknowledged organizational learning as a key factor for creating competitive advantage for companies in early 1990. However, studies on informal learning in this connection are still in their infancy. This paper contributes to an emerging field of 'small data' research on Twitter by presenting a case study of how community managers in Finland used this social media platform to construct an informal learning environment around an annually organized conference. In the empirical study authors explore informal learning behavior in project contexts especially by analyzing and visualizing informal learning behavior from Twitter data from conference participants.

\subsection{Improving the MOOC learning outcomes throughout informal learning activities}

Next paper is devoted to explore the relationship between the Massive Open Online Courses (MOOC) and informal learning. MOOC were born as a space where the university could offer training outside of the boundaries of the classroom and based on informal and social learning. The characteristics of the MOOC: massification, heterogeneity of profiles, professions, educational levels and origin, to encourage informal learning by means of social technology. Nevertheless, the current MOOC are based on methodologies and technology linked with formal learning, moving the university academic model to the so-called XMOOC. This article shows how an XMOOC has been designed and imparted integrating informal learning activities. The study demonstrates that people that have undertaken activitíes based on informal learning have a better perception of the result of their learning. Similarly, those activities break current boundaries of the MOOC as is the continuity of the learning once the MOOC has been completed. The study also deals with establishing variables that allow the identification of a profile with willingness to carry out informal learning activities.

\subsection{Knowledge Management Ecosystem based on Drupal platform for promoting the collaboration between Public Administrations}

The last paper of this track presents a technological ecosystem deployed in the Spanish Public Administration in order to assist to the knowledge management of the involved institution.

\section{REFERENCES}

[1] Berlanga, A.J., Sloep, P.B., Brouns, F., Bitter-Rijpkema, M.E., and Koper, R., 2008. Towards a TENCompetence ePortfolio. International Journal of Emerging Technologies in Learning 3, 24-28.

[2] CEDEFOP, 2009. European guidelines for validating non-formal and informal learning. Office for Official
Publications of the European Communities, Luxembourg.

Davis, F.D., 1989. Perceived Usefulness, Perceived Ease of Use, and User Acceptance of Information Technology. MIS Quarterly 13, 3, 319-340.

[4] García-Peñalvo, F.J., Conde, M.Á., Johnson, M., and Alier, M., 2013. Knowledge Co-Creation Process Based on Informal Learning Competences Tagging and Recognition. International Journal of Human Capital and Information Technology Professionals (IJHCITP) 4, 4, 18-30. DOI= http://dx.doi.org/10.4018/ijhcitp.2013100102.

[5] García-Peñalvo, F.J., Conde, M.Á., Zangrando, V., García-Holgado, A., Seoane, A.M., Alier, M., Galanis, N., Brouns, F., Vogten, H., Griffiths, D., Mykowska, A., Ribeiro-Alves, G., and Minović, M., 2013. TRAILER Project (Tagging, Recognition, Acknowledgment of Informal Learning Experiences). A Methodology to Make Learners' Informal Learning Activities Visible to the Institutions. Journal of Universal Computer Science $19,11,1661-1683$.

[6] García-Peñalvo, F.J., González-González, J.C., and Murray, M., 2012. MyElvin: A Web-Based Informal Learning Platform for Languages Practice. International Journal of Knowledge Society Research 3, 1, 26-39.

[7] García-Peñalvo, F.J., Johnson, M., Ribeiro Alves, G., and Minovic, M., 2014. Informal learning recognition through a cloud ecosystem. Future Generation Computer Systems 32, 282-294. DOI= http://dx.doi.org/http://dx.doi.org/10.1016/j.future.2013. 08.004 .

[8] García-Peñalvo, F.J., Zangrando, V., García-Holgado, A., Conde, M.Á., Seone Pardo, A.M., Alier Forment, M., Janssen, J., Griffiths, D., Mykowska, A., Ribeiro Alves, G., and Minovic, M., 2012. TRAILER project overview: Tagging, recognition and acknowledgment of informal learning experiences. In Proceedings of the 2012 International Symposium on Computers in Education (SIIE) (Andorra La Vella, Andorra. October 29-31, 20122012), Institute of Electrical and Electronics Engineers.

[9] García-Peñalvo, F.J., Zangrando, V., García-Holgado, A., Conde-González, M.Á., Seoane-Pardo, A.M., Alier, M., Galanis, N., López, J., Janssen, J., Brouns, F., Finders, A., Berlanga, A., Sloep, P., Griffiths, D., Johnson, M., Waszkiewicz, E., Mykowska, A., Minovic, M., Milovanovic, M., Marques, M.A., Viegas, M.C., and Alves, G., 2013. A Tool to Aid Institutions Recognize Their Employees Competences Acquired by Informal Learning. In Scaling up Learning for Sustained Impact. 8th European Conference onTechnology Enhanced Learning,EC-TEL2013. Paphos, Cyprus, September 17-21, 2013 Proceedings (Paphos, Cyprus, September 17-21, 2013), D. Hernández-Leo, T. Ley, R. Klamma and A. Harrer Eds. Springer Verlag, Berlin, Heidelberg, 552-555. DOI= http://dx.doi.org/10.1007/978-3-642-40814-4 56.

[10] Marques, M.A., Viegas, M.C., Alves, G.R., Zangrando, V., Galanis, N., Janssen, J., Waszkiewicz, E., Conde, M.Á., and García-Peñalvo, F.J., 2013. Managing Informal Learning in professional contexts: the learner's perspective. In Proceedings of the Workshop on Solutions that Enhance Informal Learning Recognition (WEILER 2013). Co-located with 8th European 
Conference on Technology Enhanced Learning (ECTEL 2013) (Paphos, Cyprus, September 18, 2013), F.J. García-Peñalvo, M.Á. Conde and D. Griffiths Eds. CEUR Workshop Proceedings, 39-47.

[11] Viegas, C., Marques, M., Alves, G., Galanis, N., and García-Peñalvo, F.J., 2013. Managing Informal Learning in Engineering Contexts. In Proceedings of the 2013 1st International Conference of the Portuguese Society for Engineering Education (CISPEE). (Oct 31-
Nov 01 2013, ISEP, Porto, Portugal) IEEE. DOI= http://dx.doi.org/10.1109/CISPEE.2013.6701982.

[12] Viegas, C., Marques, M., Alves, G., Mykowska, A., Galanis, N., Alier, M., Brouns, F., Janssen, J., GarcíaPeñalvo, F.J., García-Holgado, A., Zangrando, V., and Conde-González, M.A., 2014. TRAILER - a Tool for Managing Informal Learning. International Journal of Human Capital and Information Technology Professionals (IJHCITP) In Press. 